\title{
The relationship of hemoglobin concentration and signal intensity changes in oxygenation-sensitive cardiovascular magnetic resonance imaging
}

\author{
Gobinath Nadeshalingam ${ }^{1 *}$, Dominik P Guensch ${ }^{2,1}$, Kady Fischer ${ }^{1}$, Matthias G Friedrich ${ }^{1}$ \\ From 18th Annual SCMR Scientific Sessions \\ Nice, France. 4-7 February 2015
}

\section{Background}

Oxygenation-sensitive cardiovascular magnetic resonance (OS-CMR) has become a feasible diagnostic imaging modality for monitoring changes of myocardial oxygenation. Yet, potential confounding factors of this technique are not well understood. Due to T2 effects caused by tissue water content, the hydration status may impact signal intensity. We aimed at quantifying the confounding effect of a significant change of the hydration status in humans on the observed signal intensity (SI) in OS-CMR images.

\section{Methods}

Eighteen healthy volunteers underwent OS-CMR using a clinical 3T MRI system. Hemoglobin ( $\mathrm{Hb})$ concentrations were measured at baseline and immediately following rapid crystalloid infusion of $1,000 \mathrm{ml}$ of Lactate Ringer's solution (LRS). OS-CMR images were acquired in a mid-ventricular short axis view. Myocardial SI was measured in end-systolic frames during a maximal voluntary breath-hold, after a 60-second period of hyperventilation. SI changes between beginning and end of breath-holds were expressed relative to baseline (\% change).

\section{Results}

The infusion resulted in a significant decrease in measured Hb $(142.0 \pm 3.6$ vs. $129.7 \pm 3.6 \mathrm{~g} / \mathrm{L} ; \mathrm{p}<0.001)$, while SI increased by $3.6 \pm 1.4 \%$ between baseline images at normoand hypervolemia $(\mathrm{p}<0.05)$. There was a weak yet significant negative correlation between $\mathrm{Hb}$ concentration and $\mathrm{SI}$ at baseline $(\mathrm{r}=-0.48, \mathrm{p}<0.01)$. For both, hyperventilation and the SI changes induced by apnea were attenuated after hemodilution (fig. 1a, p<0.05). The extent of the SI change induced by hemodilution was correlated to the change of $\mathrm{Hb}$ (fig. 1b).
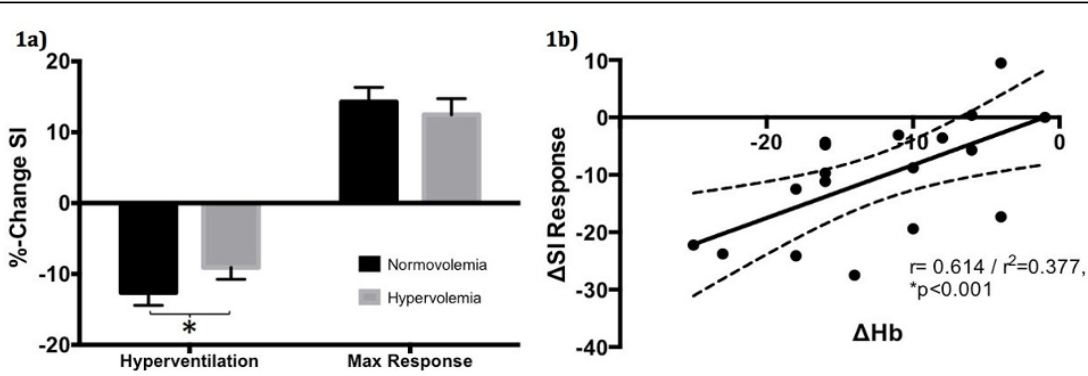

Figure 1 a) \%-change in OS-SI at normo- and hypervolemia in response to hyperventilation and maximal apnea $\left({ }^{*} p<0.05\right)$; b) Correlation between the difference in $\mathrm{Hb}(\mathrm{g} / \mathrm{L})$ and the difference in \%Sl-change between baseline and hemodilution during maximal vasodilation $(r=0.61, p<0.001)$.

'Philippa and Marvin Carsley CMR Research Centre, Montreal Heart Institute,

Montreal, QC, Canada

Full list of author information is available at the end of the article 


\section{Conclusions}

The hydration status may be a significant confounder in OS-CMR imaging. Hypervolemia leads to an increase in SI at baseline and attenuates the SI response during vasoactive breathing maneuvers. The linear correlation between $\mathrm{Hb}$ changes and differences in OS-SI changes may allow for establishing correction factors for $\mathrm{Hb}$.

\section{Funding}

N/A.

\section{Authors' details}

'Philippa and Marvin Carsley CMR Research Centre, Montreal Heart Institute, Montreal, QC, Canada. ${ }^{2}$ Anesthesiology and Pain Therapy, Bern University

Hospital - Inselspital, Bern, Switzerland.

Published: 3 February 2015

doi:10.1186/1532-429X-17-S1-Q110

Cite this article as: Nadeshalingam et al:: The relationship of hemoglobin concentration and signal intensity changes in oxygenation-sensitive cardiovascular magnetic resonance imaging. Journal of Cardiovascular Magnetic Resonance 2015 17(Suppl 1):Q110.

Submit your next manuscript to BioMed Central and take full advantage of:

- Convenient online submission

- Thorough peer review

- No space constraints or color figure charges

- Immediate publication on acceptance

- Inclusion in PubMed, CAS, Scopus and Google Scholar

- Research which is freely available for redistribution

Submit your manuscript at www.biomedcentral.com/submit
C Biomed Central 